Original article

\title{
Complementary feeding practices of tribal mothers to their Infants and Young Children in Kerala
}

\author{
Justin P. Jose ${ }^{a, *}$, Shanuga J. Cherayi ${ }^{a}$, Sreejith Sudhakar ${ }^{b}$, Kanmani T. Raju ${ }^{c}$ \\ a Dharmagiri Jeevas Social Centre, Kannur, Kerala, India \\ ${ }^{\mathrm{b}}$ Department of Clinical Psychology, Manipal College of Health Professions, Manipal Academy of Higher Education, Manipal, Udupi, Karnataka, India \\ ${ }^{\mathrm{c}}$ Department of Psychiatric Social Work, National Institute of Mental Health and Neuro Sciences, Bengaluru, Karnataka, India
}

\section{A R T I C L E I N F O}

\section{Keywords:}

Breastfeeding

Complementary feeding

Infants

Tribal mothers

\begin{abstract}
A B S T R A C T
Problem: As WHO recommends, timely and optimal introduction of complementary feeding (CF) at 6th month as it complements additional energy and growth needs of young children. We know relatively little about $\mathrm{CF}$ practices of tribal mothers in the context of high rate of poor health and under nutrition in tribal children of Kerala. This study therefore examined the factors influencing CF practices to tribal infants and young children. Methods: We conducted a community based cross-sectional survey of 1150 tribal mother-infant pairs from five districts. We used pre-tested interview schedule for data collection. Alongside descriptive statistics, we used multiple linear regression for data analyses.

Results: Around $76.2 \%$ continued $\mathrm{BF}$ at 6 th month, $62.7 \%$ introduced $\mathrm{CF}$ at 6 th month, $22.7 \%$ children received low or potentially harmful CF, $48.4 \%$ children received harmful CF and merely $8.6 \%$ received optimal CF. The maternal education, marital status, age at first pregnancy optimized CF and occupational status, hours of work per day, work status before pregnancy and age at marriage were inversely associated with $40 \%$ of variance $\left(\mathrm{R}^{2}=\right.$ 0.40). Tribal mothers' breastfeeding duration and frequency of child bathing significantly increased optimal CF and children' age at CF initiation. The poor breastfeeding at public place inversely associated with $44.7 \%$ variance $\left(\mathrm{R}^{2}=0.447\right)$. Tribal mothers' perceived difficulty for breastfeeding at public space increased CF scores and mothers who early initiated CF were more likely to feed children less-optimal $\left(\mathrm{R}^{2}=0.365\right)$.

Conclusion: Tribal mothers practice predominantly poor and potentially harmful CF to young children aged 6-24 months.
\end{abstract}

\section{Introduction}

Tribals of Kerala are heterogeneous social category demographically, culturally, socially, linguistically and on key health indicators. ${ }^{1-3}$ Therefore, there are considerable variations in current state of development characterised by a sharp human development divide between tribal and non-tribal communities. ${ }^{4}$ Tribal children are susceptible for developing malnutrition due to systematic vulnerabilities such as poverty, illiteracy, increased parental substance abuse and poor health that varyingly influence household capacities to afford adequate and appropriate dietary intake. ${ }^{5}$ There are evident diversity across different tribal communities on initiation of complementary feeding (here after $\mathrm{CF}$ ), its frequency, quality and associated hygiene practices. Hence, developing state level data-base on infant feeding practices among tribal communities was critical to improve current knowledge and to strategize existing CF practices (see Table 1, Fig. 1).

Situating within these structural vulnerabilities in general, optimal $\mathrm{CF}$ practices were critical to prevent malnutrition in children. Hence, examining the existing breastfeeding and CF practices, for their adequacy and appropriateness, were critical to develop context specific knowledge to address malnutrition in tribal children in later life. Relatively less amount of systematic studies were available on CF practices in Kerala in comparison to the eastern and central Indian tribes (e.g., Refs. 6-18.

Given these diverse and varying standards of CF practices across different tribal groups; relatively less systematic knowledge base addressing unique socio-cultural practices associated with CF practices in tribal communities; importance of optimal CF practices as per WHO

\footnotetext{
* Corresponding author. Dharmagiri Jeevas Social Centre, Kakkenchal, Cherupuzha (P.O), 670511, Kannur, Kerala, India.

E-mail addresses: josephjustinean@gmail.com (J.P. Jose), shanugac@gmail.com (S.J. Cherayi), dsmsgsa@gmail.com (S. Sudhakar), kanmani.raju@gmail.com (K.T. Raju).
} 
Table 1

Shows the sample size and selection procedures.

\begin{tabular}{lllll}
\hline $\begin{array}{l}\text { Districts } \\
\text { covered }\end{array}$ & $\begin{array}{l}\text { Blocks } \\
\text { covered }\end{array}$ & $\begin{array}{l}\text { Village } \\
\text { panchayats } \\
\text { covered }\end{array}$ & $\begin{array}{l}\text { Tribal } \\
\text { Hamlets } \\
\text { Covered }\end{array}$ & $\begin{array}{l}\text { Mothers } \\
\text { interviewed }\end{array}$ \\
\hline Kassargod & 3 & 5 & 58 & 150 \\
Kannur & 4 & 9 & 90 & 150 \\
Wayanad & 3 & 9 & 94 & 300 \\
Palakkad & 1 & 3 & 81 & 250 \\
Idukki & 3 & 12 & 98 & 300 \\
Total & 14 & 38 & 421 & 1150 \\
\hline
\end{tabular}

standard protocol ${ }^{19,20}$; locating within background of high level of malnutrition in tribal children ${ }^{12}$; lack of systematically produced knowledge base on barriers to timely $\mathrm{CF}$ initiation, indeed justify the need for this study to examine the existing CF practices of tribal communities.

\section{Materials and method}

This population based cross-sectional survey was conducted after receiving approval from the Institutional Review Board of Dharmagiri Jeevas Social Centre, a DSIR certified voluntary organization working in the areas of social marginality and health in Kerala, located at Cherupuzha of Kannur district in Kerala (DJSC/IRB/M002-2017; dated: 1803-2017. We obtained a written permission from Kerala State Tribal Directorate to access tribal habitats in selected districts. This study was based on the data from the survey phase of a 3 year ICMR Adhoc Research Project (2017-20) in Kerala.
The study universe constituted all breastfeeding tribal mothers in Kerala whereas the study sample was defined as: 'breast feeding tribal mother-infant pairs in five selected districts, whose infants were aged between 0 and 24 months of old at the time of interview.' We considered 0-24 months age range due to its critical role for optimal infant and young child feeding for optimal child growth, survival and health that sustain beyond. ${ }^{19}$ As evident in the sample definition, we included a household to study, if a mother is of a tribal origin, belong to any of five selected districts viz., Kassargod, Kannur, Wayanad, Idukki and Palakkad with an infant or young child aged between 0 and 24 months of age.

\subsection{Sample size and selection procedure}

Using OpenEpi (http://www.openepi.com/SampleSize/SSCC.htm) of the Centre for Disease Control, we estimated the sample size for this cross-sectional survey. Tribal women's population size (as per ${ }^{21}$ was (N) 534202 and hypothesized percent of outcome factor in the population was (p) $75 \% \pm 5$. Confidence limits was $5 \%$ with a design effect of 1 with a confidence level of $99.9 \%$ we obtained a sample size of 1134 . Thus the calculated sample size is 1134, which is rounded up to into 1150 .

The sample selection procedure involved multiple stages. Firstly, out of 14 districts of the state, we selected 5 districts namely Kassargod, Kannur, Wayanad, Palakkad and Idukki since they have sizable tribal population approximately ranging from $1 \%$ to $17 \%$ of its district population, which accounted for about $76 \%$ of the state tribal population. Secondly, we identified 38 village panchayats from 14 development blocks of five districts with sizable tribal population by using District Panchayat Level Statistics (Dept. of Economics and Statistics, Govt. of

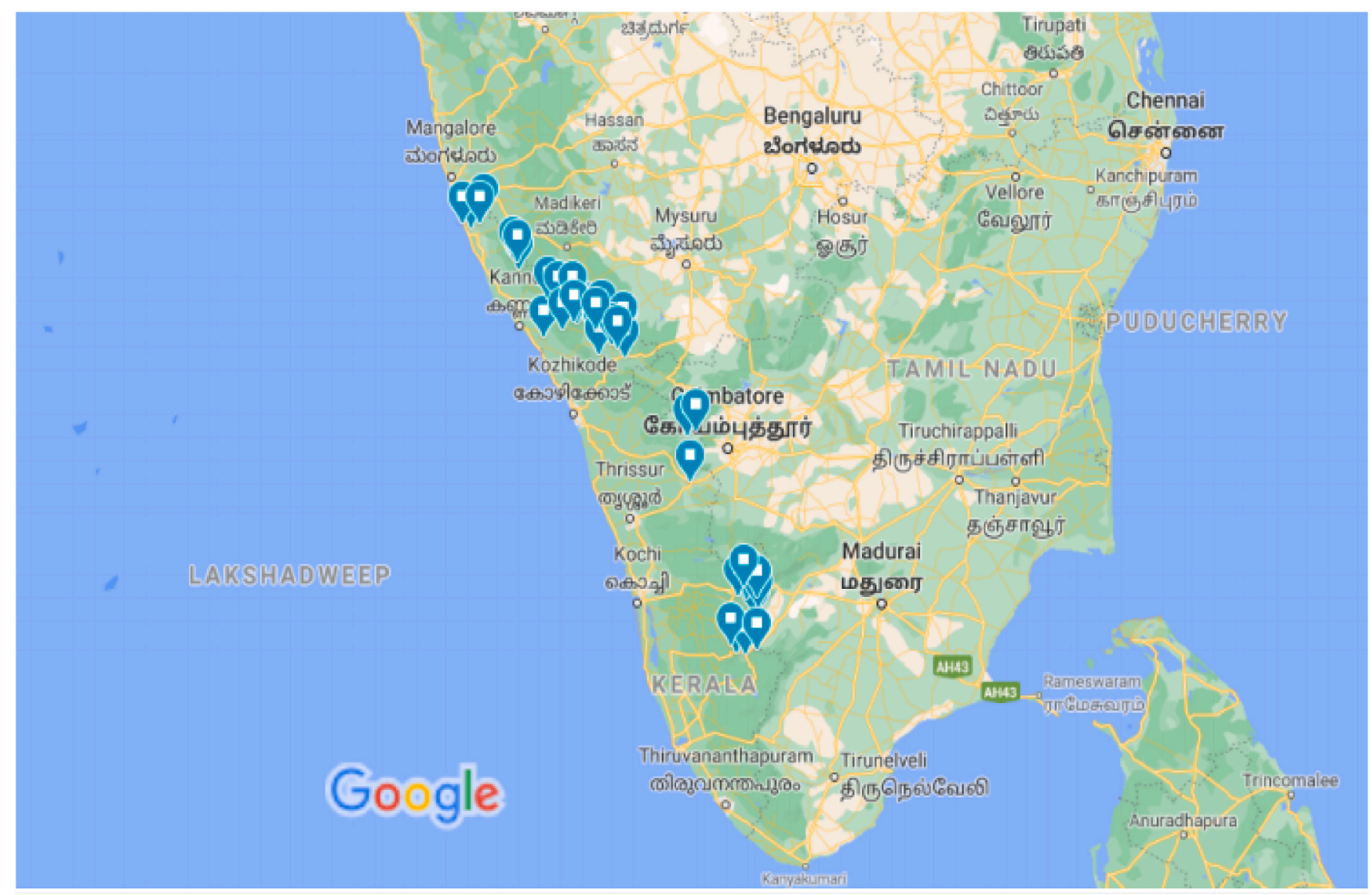

Fig. 1. Shows the sample-selected districts that details the selected blocks and panchayats

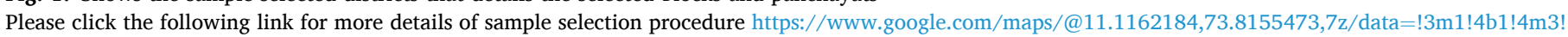

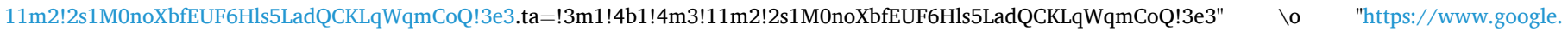
com/maps/@11.1162184,73.8155473,7z/data=!3m1!4b1!4m3!11m2!2s1M0noXbfEUF6Hls5LadQCKLqWqmCoQ!3e3" 
Kerala). In so selected village panchayats, our research team directly approached village panchayats to obtain list of 764 tribal hamlets, out of which this survey has covered 421 tribal hamlets (locally known as either colony or 'Uoors') through random selection of hamlets. Thirdly at each selected tribal hamlet, we developed a detailed list of breastfeeding tribal mothers with the help of counsellors, ICDS centres and ASHA. And this list of breastfeeding were used as primary sampling units (PSUs) from which final study units were drawn. Nearly $50-60 \%$ of the enlisted breastfeeding mothers were approached for informed consent and subsequent participation in structured interviews. The trained interviewers have contacted every alternate household by using systematic sampling to select final study unit (i.e., tribal feeding mothers) adhering to the prior set inclusion criteria and subsequent interviews.

\subsection{Ethical issues approval}

The research proposal was submitted for approval from the Institutional Review Board dually constituted for the purpose, of the Dharmagiri Jeevas Social Centre as per the Guidelines of Indian Council of Medical Research (ICMR New Delhi). Written consent was obtained from tribal mothers after explaining a brief on the purpose, nature and benefits of participation in the surveys. All participants were informed that personally identifying information such as name shall be confided. Confidentiality was ensured during the entire study tenure such as data collection and data analysis.

\section{Measures}

We used an interviewer-administered-questionnaire that consisted of socio-demographic profiles of mothers, fathers and young children. The mothers' profile contained age, education, occupation, marital status, age at marriage, age at first pregnancy, working hours and earning per day. The child profile contained age in months, gender, birth weight, and birth order. The fathers' profile contained age, education, occupation and earning per day.

A 9-item Standard of Living Index ${ }^{22}$ was used to examine the living standard of tribal mothers. Items were type of house, toilet facility, source of lighting, main fuel for cooking, source of drinking water, separate room for cooking, own agricultural land, livestock and ownership of durable goods.

We used a modified 16-item Complementary Feeding Index (CFI), which was originally developed by ${ }^{23}$ to measure frequency, adequacy and appropriateness of CF alongside initiation time and continued breastfeeding. With the addition of two items, the modified CFI taped continued $\mathrm{BF}$ at 6th month, bottle feeding, timely CF initiation, dietary diversity for the past $24 \mathrm{~h}$, food frequency for the past 7 days, meal frequency over the past $24 \mathrm{~h}$ across different age groups of 6-8 months, 9-11 months and 12-24 months. The original scale contained 14 items with a minimum score of 3 to maximum of 23 but the modified CFI had a minimum of 3 to maximum of 31 scores. These were divided into three equal groups or each group contains one third of the scores with order of low to high. Hence, the scores were divided from 3 to 12.3 as potentially low/harmful CF practices (0); from 12.4 to 21.6 as medium/harmful practice (1), and from 21.7 to 31 high or positive CF practice (2).

We used additional questions to elicit information on mothers' breastfeeding duration, frequency of bathing to child, reasons for early $\mathrm{CF}$ and perceived $\mathrm{BF}$ benefits to children and mothers, diverse $\mathrm{BF}$ breastfeeding practices.

\section{Analysis}

For descriptive analysis, we used frequency, percentile, mean and standard deviations. For multiple linear regression analysis, we grouped socio-demographic characteristics into three viz., breastfeeding mothers, children and fathers. And then, we tested the plausible role of multi-collinearity using tolerance and variance inflation factor (VIF).
The multicollinearity exist when tolerance is below 0.1 and VIF is greater than 10. In tested models, tolerance level were within the acceptable limits (i.e., less than 0.1 ) and VIF less than 10.

\section{Results}

Table 2 summarizes the socio-demographic characteristics of tribal mothers. The mothers' mean age was $26.5(S D=4.9)$ years where $47.1 \%$ aged between 19 and 25 years and $46.6 \%$ aged between 26 and 36 years. The mean years of education was $8.1(\mathrm{SD}=4.3)$ years where $34.3 \%$ were high schooled and $18.2 \%$ were not formally schooled. Nearly $97.5 \%$ were married and $82.2 \%$ were housewives. Among working mothers, mean working hours was $1.6(\mathrm{SD}=3)$ hours, $2.2(\mathrm{SD}=2.8)$ days per week, and mean earning per day was $107.9(\mathrm{SD}=156)$.

Nearly $41.4 \%$ of the mothers were working before pregnancy. The mothers' mean age at marriage was $22.1(\mathrm{SD}=3.4$ ) years and $30.7 \%$ reported early marriage between 13 and 18 years of age, although $61.6 \%$ were married during their age between 19 and 25 years. Nearly $7 \%$ of tribal mothers had early pregnancy before the age of 18 years and $77.2 \%$ had pregnancy during the age between 19 and 25 years.

Table 3 summarizes socio-demographic characteristics of young children and their fathers. The mean age of young children was 11.7 (SD $=7.1$ ) months where $28.7 \%$ were aged between 0 and 6 months and $71.3 \%$ were aged between 7 and 24 months. In children's gender, $51.5 \%$ were males and $48.5 \%$ were females. In birth intervals, $43.8 \%$ were first children, $6.5 \%$ reported elder children were aged less than 24 months, $20.3 \%$ reported elder child belong to the age group of 25-48 months, and $29.4 \%$ reported elder one to the indexed children were aged 48 months and above.

In fathers' profile, the mean age was $31(\mathrm{SD}=5.8)$ years and mean years spent for formal schooling was $7.2(\mathrm{SD}=4.1)$ years. In occupation, $70.8 \%$ were manual labourers and $6.9 \%$ were farmers and mean earning per day was $509.9(\mathrm{SD}=162)$.

As Table 4 shows, out of 1150 tribal mothers, $76.2 \%$ mothers continued breastfeeding at 6th month where only $62.7 \%$ of mothers introduced $\mathrm{CF}$ at 6 th month. Interestingly, 3.6\% $(\mathrm{n}=160)$ did not introduce $\mathrm{CF}$ at 6 th month and nearly $23.1 \%$ were currently on bottle feeding. Young children's age at CF initiation range from 0 to 12 months with a mean of $4.5(\mathrm{SD}=2.8)$ months. In Complementary Feeding Index, we obtained the scores range from 3 to 31 with a mean of 13.8 and SD 5.9. This distribution of scores were divided into terciles resulting three categories viz., low (potentially harmful), medium (harmful) and high

Table-2

Socio-demographic characteristics of tribal feeding mothers.

\begin{tabular}{llll}
\hline $\begin{array}{l}\text { Mothers' profile } \\
\text { characteristics }\end{array}$ & $\begin{array}{l}\text { Mean (SD) } \\
\text { Frequency } \\
\text { (n) }\end{array}$ & $\begin{array}{l}\text { Mothers' profile } \\
\text { characteristics }\end{array}$ & $\begin{array}{l}\text { Mean (SD) } \\
\text { Frequency } \\
\text { (n) }\end{array}$ \\
\hline Age in yrs. & $26.5(4.9)$ & Age at marriage & $22.1(3.4)$ \\
13-18 yrs. & $09(0.8)$ & $13-18$ yrs. & $353(30.7)$ \\
19-25 yrs. & $542(47.1)$ & $19-25$ yrs. & $708(61.6)$ \\
26-35 yrs. & $536(46.6)$ & $26-35$ yrs. & $87(7.6)$ \\
36-45 yrs. & $63(5.5)$ & $36-45$ yrs. & $0.2(0.2)$ \\
Education in yrs. & $8.1(4.3)$ & Age at first pregnancy & $22.1(3.4)$ \\
$\quad$ No formal schooling & $136(18.2)$ & $13-18$ yrs. & $81(7)$ \\
LP school & $129(11.2)$ & $19-25$ yrs. & $888(77.2)$ \\
UP School & $196(17)$ & $26-35$ yrs. & $177(15.4)$ \\
High school & $394(34.3)$ & $36-45$ yrs. & $04(0.3)$ \\
HSS & $192(16.7)$ & - & - \\
UG \& above & $103(9.0)$ & - & - \\
Marital status & & Working hrs. per day & $1.6(3.0)$ \\
Married & $1121(97.5)$ & Working days per week & $2.2(2.8)$ \\
Widowed/separated & $29(2.5)$ & Earning per days & $107.9(156)$ \\
Occupation & & Work status before & \\
& & delivery & \\
Homemakers & $945(82.2)$ & Yes & $476(41.4)$ \\
Manual labour & $128(11.1)$ & No & $674(58.6)$ \\
Agriculture & $23(2.0)$ & & \\
Formal sector jobs & $54(4.7)$ & & \\
\hline & & & \\
\hline
\end{tabular}


Table-3

socio-demographic characteristics of infants and young children and their fathers.

\begin{tabular}{llll}
\hline $\begin{array}{l}\text { Children's profile } \\
\text { characteristics }\end{array}$ & $\begin{array}{l}\text { Mean (SD) } \\
\text { Frequency } \\
\text { (n) }\end{array}$ & $\begin{array}{l}\text { Fathers' profile } \\
\text { characteristics }\end{array}$ & $\begin{array}{l}\text { Mean (SD) } \\
\text { Frequency } \\
\text { (n) }\end{array}$ \\
\hline Age in months & $11.7(7.1)$ & Age in years & $\begin{array}{l}31.0(5.8) \\
\text { yrs. }\end{array}$ \\
0-6 months & $330(28.7)$ & - & - \\
7-24 months & $820(71.3)$ & - & - \\
Birth weight M(SD) & $2.5(.54)$ & Years of schooling & $7.2(4.1)$ yrs. \\
Gender (Male) & $592(51.5)$ & Earning per day & $509.9(162)$ \\
Female & $558(48.5)$ & - & - \\
Birth interval & $504(43.8)$ & Fathers' occupation & Not working \\
First child & $75(6.5)$ & Manual labourer & $13(1.1)$ \\
Less than 24 months & $233(20.3)$ & Farmers & $814(70.8)$ \\
25-47 months & $338(29.4)$ & Other form of works & $244(21.2)$ \\
48 \& more months & & &
\end{tabular}

(positive) CF practices. The frequency distributions showed $22.7 \%$ were low $\mathrm{CF}$ which was potentially harmful to young children, $48.4 \%$ had received suboptimal or harmful $\mathrm{CF}$ practices and $8.6 \%$ received optimal or adequate $\mathrm{CF}$.

Effect of Parental and child characteristics on CF scores: In the first model, we examined the effect of parental and child characteristics on CF scores to tribal children (Table 5). F statistic showed an overall model, significant at 0.001 level $(\mathrm{F}(916)=33.251 ; \mathrm{p}<.001)$. The maternal education ( $\beta=0.144 ; \mathrm{p}<.001)$, marital status $(\beta=0.061 ; \mathrm{p}<$ $.05)$ and age at first pregnancy $(\beta=0.108 ; p<.05)$ significantly improved CF scores. But the occupation $(\beta=-0.163 ; \mathrm{p}<.001)$ and daily working hours $(\beta=-0.106 ; \mathrm{p}<.05)$, work status before pregnancy $(\beta=$ $-0.102 ; \mathrm{p}<.05)$ and age at marriage $(\beta=-0.118 ; \mathrm{p}<.05)$ significantly reduced CF scores. In children's profile, age significantly influenced ( $\beta$ $=0.574 ; \mathrm{p}<.001$ ) and in fathers' profile, schooling significantly improved CF $(\beta=0.091 ; p<.01)$ suggesting better paternal education improve CF practices. The overall model accounted for $40 \%$ of variance on CF practice of tribal mothers. Therefore, the results suggest that good parental schooling, being married and high age at first pregnancy significantly improved CF scores but maternal occupation, daily working hours, work status prior to pregnancy and lower age at marriage significantly reduced $\mathrm{CF}$ scores. Advancing age was associated with increased $\mathrm{CF}$ scores.

Effect of breastfeeding practices on CF scores: In second model (see Table 5), we examined the effect of breastfeeding related factors on optimal CF after controlling for parental and child characteristics. F statistic suggests that overall model was significant $(F(916)=30.097 ; p$ $<.001)$. The BF duration $(\beta=0.138 ; \mathrm{p}<.001)$ and frequency of bathing to child $(\beta=0.058 ; \mathrm{p}<.05)$ significantly increased optimal $\mathrm{CF}$ scores but children' age at CF initiation $(\beta=-0.110 ; \mathrm{p}<.001)$ and negative $B F$ at public space $(\beta=-0.080 ; \mathrm{p}<.01)$ significantly reduced optimal $\mathrm{CF}$ scores. The parental and child characteristics held constant for analysis showing significant associations were education $(\beta=0.13 ; \mathrm{p}<.001)$, marital status $(\beta=0.062 ; \mathrm{p}<.05)$, occupational status $(\beta=-0.123 ; \mathrm{p}<$ $.001)$, age at marriage $(\beta=-0.106 ; \mathrm{p}<.05)$ and children's age $(\beta=$ $0.528 ; \mathrm{p}<.001$ ). This model accounts for nearly $44.7 \%$ of variance on CF scores $\left(R^{2}=0.447\right)$. The results suggest that the tribal mothers' breastfeeding duration, frequency of bathing child significantly optimized CF scores. Further, negative breastfeeding at public space significantly reduced $\mathrm{CF}$ scores. The mothers considering $\mathrm{BF}$ at public space as difficult has an improved scores on CF. Nonetheless, feeding mothers who initiated early $\mathrm{CF}$ tend to feed their children less optimal.

Effect of breastfeeding practices on age at CF initiation: In third model (see table- 5), we examined the breastfeeding factors influencing age at $\mathrm{CF}$ initiation. F statistic shows a significant model (F (1149) = 140.017; $\mathrm{p}<.001$ ). None of the maternal characteristic significantly influenced children's age at CF initiation. Instead, children's present age significantly associated with age at CF initiation $(\beta=0.544 ; \mathrm{p}<.001)$, alongside mothers' plan for long duration of breastfeeding increased age at CF initiation $(\beta=0.057 ; \mathrm{p}<.05)$. The general household standard of living $(\beta=0.095 ; \mathrm{p}<.05)$ and mothers positive feeding at public space significantly increased age at CF initiation. The overall model accounted for $36.5 \%$ variance on age at $C F$ initiation $\left(R^{2}=0.365\right)$. Hence, the results suggest that children's age, plan for long duration of

Table-4

Frequency and percentage distribution of item wise CF scores (CFI).

\begin{tabular}{|c|c|c|c|c|c|c|}
\hline \multicolumn{3}{|c|}{ Introduction of fluid, semi-solid and solid foods } & Frequency (\%) & \multicolumn{2}{|c|}{ CFI scores categorized } & Frequency (\%) \\
\hline \multicolumn{3}{|c|}{ Is your child on breastfeed after 6 months } & & \multicolumn{2}{|c|}{ Low: Potentially harmful CF } & $261(22.7)$ \\
\hline \multicolumn{3}{|l|}{ Yes } & $876(76.2)$ & \multicolumn{2}{|c|}{ Medium: harmful CF } & $557(48.4)$ \\
\hline \multicolumn{3}{|l|}{ No } & $41(3.6)$ & \multicolumn{2}{|c|}{ High: Positive CF } & $99(8.6)$ \\
\hline \multicolumn{3}{|l|}{ Less than 6 months } & $233(20.3)$ & \multicolumn{2}{|c|}{ Infants less than 6 months } & $233(20.3)$ \\
\hline \multicolumn{3}{|c|}{ Did you introduce CF at 6 th month? } & & \multicolumn{2}{|c|}{ CFI descriptive scores } & Mean (SD) \\
\hline \multicolumn{3}{|c|}{ Yes } & $721(62.7)$ & \multicolumn{2}{|l|}{ Min-Max } & $0-31$ \\
\hline \multicolumn{3}{|l|}{ No } & $160(3.6)$ & \multicolumn{2}{|l|}{ Mean (SD) } & $13.8(5.9)$ \\
\hline \multicolumn{3}{|l|}{ Less than 6 months } & $269(23.4)$ & \multicolumn{2}{|l|}{-} & - \\
\hline \multicolumn{3}{|c|}{ Is your child currently on bottle feed? } & & \multicolumn{3}{|c|}{ Age at $\mathrm{CF}$ initiation } \\
\hline Yes & & & $266(23.1)$ & \multicolumn{2}{|l|}{ Min-Max } & $0-12$ \\
\hline \multicolumn{3}{|l|}{ No } & $884(76.9)$ & \multicolumn{2}{|l|}{ Mean (SD) } & $4.5(2.8)$ \\
\hline CF & 6-8 months & Frequency (\%) & 9-11 months & Frequency (\%) & 12-24 months & Frequency (\%) \\
\hline MDD & 0/No times & $160(13.9)$ & 0/No times & $79(6.9)$ & 0/No times & $57(5.0)$ \\
\hline \multirow[t]{3}{*}{ Over the past $24 \mathrm{~h}$. } & 1-2 times & $453(39.4)$ & $1-2$ times & $505(43.9)$ & 1-2 times & $386(33.6)$ \\
\hline & 3 or more times & $162(14.1)$ & $4 /$ more times & $77(6.7)$ & $4 /$ more times & $151(13.1)$ \\
\hline & Not applicable & $375(32.6)$ & Not applicable & $489(42.5)$ & Not applicable & $556(48.3)$ \\
\hline \multirow[t]{4}{*}{ MMF (Over last 24 h) } & 0/No times & $87(7.6)$ & 0/No times & $42(3.7)$ & 0/No times & $32(2.8)$ \\
\hline & $1-3$ times & 160 (13.9) & $1-3$ times & $272(23.7)$ & $1-3$ times & $280(24.3)$ \\
\hline & 2 times/more & $496(43.1)$ & 2 times/more & $327(28.4)$ & 2 times/more & $284(24.7)$ \\
\hline & Not applicable & $407(35.4)$ & Not applicable & $509(44.3)$ & Not applicable & $554(48.2)$ \\
\hline \multirow[t]{5}{*}{ MDD over the past 7 days } & \multicolumn{2}{|c|}{ Staples food: grains \& tubers } & \multicolumn{2}{|l|}{ Pluses } & \multicolumn{2}{|l|}{ Animal milks } \\
\hline & 0/No times & $268(23.3)$ & 0/No times & $181(15.7)$ & 0/No times & $586(51.0)$ \\
\hline & 1-3 times & $496(43.1)$ & $1-3$ times & $553(48.1)$ & 1-3 times & $175(15.2)$ \\
\hline & 4 times/more & $76(6.6)$ & 4 times/more & $110(9.6)$ & 4 times/more & $67(5.8)$ \\
\hline & Not applicable & $310(27.0)$ & Not applicable & $306(26.6)$ & Not applicable & $322(28.0)$ \\
\hline \multirow[t]{5}{*}{ MDD over the past 7 days } & Meats and eggs & & Vitamin A-rich & \& vegetables & Other fruits \& & bles \\
\hline & 0/No times & $407(35.4)$ & 0/No times & $315(27.4)$ & 0/No times & $265(23.0)$ \\
\hline & $1-3$ times & $398(34.6)$ & $1-3$ times & $465(40.4)$ & $1-3$ times & $496(43.1)$ \\
\hline & 4 times/more & $37(3.2)$ & 4 times/more & $67(5.8)$ & 4 times/more & $85(7.4)$ \\
\hline & Not applicable & $308(26.8)$ & Not applicable & $303(26.3)$ & Not applicable & $304(26.4)$ \\
\hline
\end{tabular}


Table 5

Shows factors determining complementary feeding to young children.

\begin{tabular}{|c|c|c|c|}
\hline Predictor variables & $\begin{array}{l}\text { Complementary } \\
\text { feeding }\end{array}$ & $\begin{array}{l}\text { Complementary } \\
\text { feeding }\end{array}$ & $\begin{array}{l}\text { Age at CF } \\
\text { initiation }\end{array}$ \\
\hline (Constant) & $\beta$ & $\beta$ & B \\
\hline \multicolumn{4}{|c|}{ Mothers' characteristics } \\
\hline Age & .035 & .017 & .026 \\
\hline Education & $.144 * * *$ & $.139 * * *$ & -.002 \\
\hline $\begin{array}{l}\text { Marital status } \\
\text { (widowed, never } \\
\text { married }=0 \text { ) }\end{array}$ & $.061^{*}$ & $.062^{*}$ & -.014 \\
\hline $\begin{array}{l}\text { Occupation } \\
\quad(\text { homemakers = 0) }\end{array}$ & $-.163^{* * *}$ & $-.123^{* * *}$ & -.033 \\
\hline Daily working hours & $-.106^{*}$ & -.069 & -.050 \\
\hline $\begin{array}{l}\text { Work before } \\
\text { pregnancy }(\text { no }=0)\end{array}$ & -.102 & -.094 & -.014 \\
\hline Weekly working days & .092 & .049 & .067 \\
\hline Daily earning & .003 & .012 & -.008 \\
\hline Age at marriage & $-.118^{*}$ & $-.106^{*}$ & -.023 \\
\hline Age at first pregnancy & .108 & .097 & .007 \\
\hline \multicolumn{4}{|c|}{ Children's characteristics } \\
\hline $\begin{array}{l}\text { Age (in completed } \\
\text { months) }\end{array}$ & $.574 * * *$ & $.528^{* * *}$ & $.544 * * *$ \\
\hline Sex $($ female $=0)$ & .032 & .023 & .035 \\
\hline Birth weight & -.011 & - & - \\
\hline $\begin{array}{l}\text { Type of child birth } \\
\quad \text { (surgical }=0 \text { ) }\end{array}$ & .009 & - & - \\
\hline \multicolumn{4}{|l|}{ Fathers' characteristics } \\
\hline Fathers' age & .026 & .030 & .010 \\
\hline Education & $.091^{* *}$ & .053 & .004 \\
\hline $\begin{array}{l}\text { Occupation (not- } \\
\text { working =0) }\end{array}$ & -.004 & - & - \\
\hline Daily earning & -.010 & .014 & -.040 \\
\hline \multicolumn{4}{|l|}{ Test variables } \\
\hline Breastfeeding duration & - & $.138^{* * *}$ & $.057^{*}$ \\
\hline $\begin{array}{l}\text { Frequency of bathing } \\
\text { child }\end{array}$ & - & $.058^{*}$ & -.011 \\
\hline Standard of living & - & .037 & $.095 * * *$ \\
\hline $\begin{array}{l}\text { Early complementary } \\
\text { feeding }\end{array}$ & - & $-.110 * * *$ & -.034 \\
\hline $\begin{array}{l}\text { Perceived BF benefits } \\
\text { to child }\end{array}$ & - & .002 & -.015 \\
\hline $\begin{array}{l}\text { Perceived BF benefits } \\
\text { to mother }\end{array}$ & - & .004 & -.039 \\
\hline Poor breastfeeding & - & -.053 & .009 \\
\hline $\begin{array}{l}\text { Negative BF at public } \\
\text { space }\end{array}$ & - & $-.080 * *$ & .002 \\
\hline $\begin{array}{l}\text { Positive BF at public } \\
\text { space }\end{array}$ & - & .068 & $-.063^{*}$ \\
\hline F (916) & $33.251^{* * *}$ & $30.097 * * *$ & $140.017^{* * *}$ \\
\hline $\mathrm{R}^{2}$ & 0.40 & 0.447 & 0.365 \\
\hline
\end{tabular}

Dependent variable: complementary feeding score. ${ }^{*} \mathrm{p}<.05 ; * * \mathrm{p}<.01 ; * * \mathrm{p}<$ .001 .

breastfeeding, standard of living and positive breastfeeding at public spaces significantly delayed the age at CF initiation.

\section{Discussion}

Out of 1150 tribal mother-infant pairs from five districts in the state, $76.2 \%$ continued BF at 6 th month and $62.7 \%$ introduced $\mathrm{CF}$ at 6 th month. Interestingly, 3.6\% did not introduce CF at 6 th month and $23.1 \%$ were currently on bottle feeding. The mean age for CF initiation was 4.5 $(\mathrm{SD}=2.8)$ months. Nearly $22.7 \%$ were low/potentially harmful $\mathrm{CF}$, $48.4 \%$ received harmful $\mathrm{CF}$ while only $8.6 \%$ received optimal CF among tribal children. The mothers' schooling, being married, higher age at first pregnancy, children's age and fathers' education have significantly improved CF. But being working, more daily working hours and work status before pregnancy significantly reduced CF scores. Also, mothers who considered $\mathrm{BF}$ at public space as difficult to practice had high scores on CF. Nonetheless, feeding mothers who initiated early CF tend to feed their children less optimal. Further, children's age, long duration of breastfeeding, better standard of living and optimal breastfeeding at public space significantly postponed the age at CF initiation.

Breastfeeding is a universal and prolonged in tribal communities in the state as elsewhere. ${ }^{9,24-27}$ We found nearly $76 \%$ of the tribal mothers continued to breastfeed their young children at 6 th months where only $3.6 \%$ weaned out at 6 th month.

${ }^{19}$ WHO recommends CF initiation at 6 th month that subsequently improve sizably during 8-12 months. Nonetheless, studies among tribal mother-infant pairs from different parts of India evidenced highly inconsistent and conflicting complementary feeding practices, which were grossly inadequate and suboptimal to infants growth and survival. ${ }^{6-8,28,29}$ Largely, these inconsistencies in CF practices were observed in terms of early and delayed CF, which range from 3 to 6 months and 6 months to even 1 year. Invariably, out of randomly selected 1150 tribal mother-infant pairs from five districts, $62.7 \%$ tribal mothers introduced $\mathrm{CF}$ at 6 th month; whereas the mean $\mathrm{CF}$ initiation age was 4.5 months with a SD of 2.8 months. At state level, NFHS-4 (2015-16) estimates $63.1 \%$ children aged received CF between 6 and 8 months.

However, NFHS-4 (2015-16) estimates the breastfeeding children receiving adequate diet during age between 6 and 23 months were $23.1 \%$ in the state. In this study estimated nearly $22.7 \%$ children aged between 6 and 24 months received low or highly harmful amount of CF and $48.4 \%$ received harmful CF; while only $8.6 \%$ received optimal CF among tribal children. Results evidently suggest the need to develop tribal population based intervention to strengthen optimal CF practices to tribal children during 6-23 months.

Tribal mothers' education, being married, higher age at first pregnancy, children's age and fathers' better education have significantly optimized CF. But being working, more daily working hours and work status before pregnancy significantly reduced optimal CF to young children.

Tribal mothers' education, marital status and age at pregnancy were significantly associated with children's age at CF initiation. Invariably, Sisay, Edris and Tariku ${ }^{30}$ found maternal education and marital status predicted optimal CF practice alongside other factors such as maternal occupation, household wealth status, post-natal care and health extension visits. However, hours spent for working outside homes, number of working days per week contributed significantly to poor and suboptimal CF practices in tribal mothers.

As evidenced in the studies from other parts of India (e.g., Refs. 31-33, we found that the mothers' years for schooling, being married, higher age at first pregnancy, children's age and fathers' better education significantly optimized CF. But being working, more working hours per day and work status before pregnancy have significantly reduced optimal CF to young children. Results suggested that poor socio-economic conditions of tribal women lead them to work more hours per day and more number of days per week while leading children at homes with other family members. As a result, tribal mothers needs educative interventions alongside support services during the entire child bearing and breastfeeding tenures, through incentives for lost working days and incentives for mothers under existing maternal and child welfare schemes at state and national level.

The maternal proactive breastfeeding associate with quality of $\mathrm{CF}$ received by their children at 6 th month. ${ }^{34}$ The mothers who practice optimal breastfeeding such as timely breastfeeding initiation, exclusive breastfeeding for first six months with frequency of 8-12 times a day tend to initiate timely $\mathrm{CF}$ to their children. In contrary to these, we found mothers who initiated early CF tends to feed children less optimal. In addition, we found tribal mothers, who considered $\mathrm{BF}$ at public space as more difficult to practice had high scores on CF. It is because; such mothers tend to initiate early $\mathrm{CF}$ to complement the breastfeeding related difficulties in public spaces.

Moreover, our results suggested that children's age, long duration of breastfeeding, standard of living and optimal breastfeeding at public spaces significantly postponed the age at CF initiation. Invariably, less optimal CF practices results from poor social and economic conditions of 
the households, ignorance, poor family wealth status, and access related barriers to prenatal health education. $6,7,28$

The study limitations: The data generated by using a cross-sectional survey design has inherent design level limitation to capture cause and effect relationships. The survey has not attempted to include a matched comparison group of non-tribal rural mothers. Such an approach would have enabled the researchers to compare many of the sociodemographic characteristics to generate more reliable statistical inferences. Also in standard of living index, we adopted only initial 8 out of 27 items. All 27 items index would have given more robust estimate of general household standard of living of tribal infant-mother pairs. Hence, the readers may be considered these limitations in mind while weighing the findings of this study.

\section{Conclusion}

This study first estimates the $62.7 \%$ introduced CF at 6 th month out of 1150 mother-infant pairs studied and then $22.7 \%$ children received potentially harmful $\mathrm{CF}$ and $48.4 \%$ received harmful CF. Evidently, $8.6 \%$ young children received optimal $\mathrm{CF}$ among tribal children, which reiterate the need for structural interventions to systematically address this issues. Maternal and paternal socio-demographic characteristics such as being married, higher age at first pregnancy, children's age and fathers' better education have significantly optimized CF. But being working, more working hours per day and work status before pregnancy have significantly reduced optimal CF to young children.

\section{Disclosure of potential conflicts of interest}

We would like to declare that none of the authors have any conflict of interest to publish the paper. This study is part of an Ad hoc project funded by Indian Council of Medical Research (ICMR), New Delhi with file no. R F C N o. RC H/Adhoc/32/2016-17 dated: March 28, 2017.

\section{Research involving human participants/animals}

This is a cross-sectional study where we have conducted surveys of tribal feeding mothers. We got approved by the Institutional Ethics Committee and apart from that all participants were informed about the need and purpose of the study and obtained written consent from them.

\section{Informed consent}

All participants were informed about the aim of the study and obtained written consent. Confidentiality were ensured throughout the study and we did not include their names and other personal identification details in the article.

\section{Consent to participate}

Informed consent was obtained from all individual participants included in the study.

\section{References}

1 Xaxa V. Protective discrimination: why scheduled tribes lag behind scheduled castes. Econ Polit Wkly. 2001:2765-2772.

2 Kakkoth S. The primitive tribal groups of Kerala: a situational appraisal. Stud Tribes Tribals. 2005;3(1):47-55.

3 Haddad S, Mohindra KS, Siekmans K, Màk G, Narayana D. "Health divide" between indigenous and non-indigenous populations in Kerala, India: population based study. BMC Publ Health. 2012;12(1):390.
4 Paul BP. Income, Livelihood And Education Of Tribal Communities In Kerala-Exploring Intercommunity Disparities (Doctoral Dissertation, PhD Thesis. Kerala: Cochin University of Science and Technology; 2013.

5 National Institute of Nutrition. Manual A. Dietary guidelines for Indians. 2011;2: 89-117.

6 Patro S, Nanda S, Sahu R. Infant feeding practices of Paroja: a tribal community of Orissa. Stud Home Community Sci. 2012;6(1):21-25.

7 Mondal TK, Sarkar AP, Shivam S, Thakur RP. Assessment of infant and young child feeding practice among tribal women in Bhatar block of Burdwan district in West Bengal, India. Int J Med Sci Publ Health. 2014;3:324-326.

8 Birdi TJ, Joshi S, Kotian S, Shah S. Possible causes of malnutrition in Melghat, a tribal region of Maharashtra, India. Global J Health Sci. 2014;6(5):164.

9 Shashank KJ, Chethan TK. A study on breastfeeding practices among mothers in rural area of Mangalore district: a cross-sectional study. Ntl J Community Med. 2016;7(2): $134-137$.

10 Bobhate PS, Shrivastava SR. Breastfeeding practices and factors associated with it: a cross sectional study among tribal women in Khardi Primary Health Centre, Thane, India. International Journal of Public Health Research. 2012;2(1):115-121.

11 Bhardwaj SL, Rathore MS, Paliwal A. A study of breast feeding and neonatal care practices in some ethnic communities in periurban slums at Jaipur Rajasthan. Anthropol. 2012;14(5):459-465.

12 Giridhar L, Lakshmi G. Practices regarding colostrums and pre-lacteals among Gadaba and Konda Dora tribes of Vizianagaram district. IOSR J Pharm. 2012;2(5): $8-12$.

13 Sharma V, Sharma A. Family planning practices among tribals of South Rajasthan India. J Res Educ Indian Med. 1991;10(4):5-9.

14 Chirmulay D, Nisal R. Nutritional status of tribal underfive children in Ahmadnagar District, Maharashtra in relation to weaning/feeding practices. Indian Pediatr. 1993; 30(2):215-222.

15 Panpanich R, Vitsupakorn K, Chareonporn S. Nutritional problems in children aged 1-24 months: comparison of hill-tribe and Thai children. Journal of the Medical Association of Thailand= Chotmaihet thangphaet. 2000;83(11):1375-1379.

16 Veena SR, Krishnaveni GV, Srinivasan K, Wills AK, Hill JC, Kurpad AV, Fall CH. Infant feeding practice and childhood cognitive performance in South India. Arch Dis Child. 2010;95(5):347-354.

17 Malhotra R, Noheria A, Amir O, Ackerson LK, Subramanian SV. Determinants of termination of breastfeeding within the first 2 years of life in India: evidence from the National Family Health Survey-2. Matern Child Nutr. 2008;4(3):181-193.

18 Swamy KB. Infant Feeding Practices Among the Slum Dwellers of Visakhapatnam City, Andhra Pradesh. Visakhapatnam: unpublished Thesis, Department of Anthropology, Andhra University; 2009.

19 World Health Organization and UNICEF. Global Strategy on Infant and Young Child Feeding. Geneva: World Health Organization; 2003. Available at: http://www.who.in t/nutrition/publications/infantfeeding/9241562218/en.

20 World Health Organization. Infant and Young Child Feeding: Model Chapter for Textbooks for Medical Students and Allied Health Professionals. Geneva, Switzerland: WHO Press; 2009.

21 Census. Cenus Report. 2011 (New Delhi, India).

22 IIPS. National Family Health Survey 1998- 99 (NFHS-2): India. Mumbai: International Institute for Population Sciences; 2000 .

23 Garg A, Chadha R. Index for measuring the quality of complementary feeding practices in rural India. J Health Popul Nutr. 2009;27(6):763.

24 Bandyopadhyay M. Impact of ritual pollution on lactation and breastfeeding practices in rural West Bengal, India. Int Breastfeed J. 2009;4(1):2.

25 Noor S, Rajesh AH, Babu GK. A study on breast feeding practices among mothers of urban slums of Rourkela. Nutrition. 2015;69:64-65.

26 Ashwini S, Katti SM, Mallapur MD. Comparison of complementary feeding practices among urban and rural mothers: a cross-sectional study. Al Ameen J Med Sci. 2014;7 (4):257-264

27 Meshram II, Arlappa N, Balakrishna N, Rao KM, Laxmaiah A, Brahmam GNV. Trends in the prevalence of undernutrition, nutrient and food intake and predictors of undernutrition among under five year tribal children in India. Asia Pac J Clin Nutr. 2012;21(4):568.

28 Dash M, Choudhury RK. Breast feeding practices among Santals and non-Santals of Orissa. Anthropol. 2005;7(4):283-287.

29 Tiwari B, Rao V, Mishra D, Thakur CSS. Infant-feeding practices among Kol tribal community of Madhya Pradesh. Indian J Community Med. 2007;32(3), 228-228.

30 Sisay W, Edris M, Tariku A. Determinants of timely initiation of complementary feeding among mothers with children aged 6-23 months in Lalibela District, Northeast Ethiopia, 2015. BMC Publ Health. 2016;16(1):884.

31 Sharma B, Giri G, Christensson K, Ramani KV, Johansson E. The transition of childbirth practices among tribal women in Gujarat, India-a grounded theory approach. BMC Int Health Hum Right. 2013;13(1):41.

32 Garje RR, Thitame SK, Somasundaram KV, Gautam L, Gite MS. Infant feeding beliefs and practices among tribal mothers in Nashik district, Maharashtra. Int J Med Sci Publ Health. 2016;5:2203-2208.

33 Laroia N, Sharma D. The religious and cultural bases for breastfeeding practices among the Hindus. Breastfeed Med. 2006;1(2):94-98.

34 Bagul AS, sahebrao Supare M. The infant feeding practices in an urban slum of Nagpur, India. J Clin Diagn Res: J Clin Diagn Res. 2012;6(9):1525. 